\title{
Эффективность преобразования перовскитных и сенсибилизированных красителем солнечных элементов при различных интенсивностях солнечного излучения
}

\author{
(C) А.Б. Никольская, С.С. Козлов, М.Ф. Вильданова, О.И. Шевалеевский \\ Институт биохимической физики им. Н.М. Эмануэля Российской академии наук, \\ 119334 Москва, Россия \\ E-mail: anickolskaya@mail.ru
}

(Поступила в Редакцию 19 ноября 2018 г.

В окончательной редакции 26 ноября 2018 г.

Принята к публикации 26 ноября 2018 г.)

Представлены результаты сравнительного исследования поведения основных фотовольтаических характеристик для перовскитных солнечных элементов (PSC), сенсибилизированных красителями солнечных элементов (DSC) и солнечных элементов на основе кристаллического кремния $(c-\mathrm{Si})$ при изменении интенсивности солнечной радиации в диапазоне $10-1000 \mathrm{BT} / \mathrm{m}^{2}$. Установлено, что в отличие от $c-\mathrm{Si}$ эффективности PSC- и DSC-фотопреобразователей при низких значениях солнечной радиации мало отличаются от соответствующих величин, наблюдаемых для стандартных условий освещения интенсивностью $1000 \mathrm{BT} / \mathrm{M}^{2}$ (AM1.5G). Показано, что высокие эффективности PSC и DSC при низкоинтенсивном и рассеянном освещении обусловлены наличием в конструкции фотопреобразователей наноструктурированных фотоэлектродов на основе диоксида титана и существенно зависят от структуры, морфологии и толщины оксидных слоев.

DOI: 10.21883/FTP.2019.04.47456.9023

\section{1. Введение}

В последние десятилетия многочисленные исследования в области солнечной фотовольтаики направлены на создание солнечных элементов (СЭ) следующего поколения, которые могли бы составить конкуренцию доминирующим на рынке традиционным фотопреобразователям на основе кремния и обладали при этом сравнимой с ними эффективностью при более дешевой технологии изготовления $[1,2]$. К основным направлениям поиска относится разработка сенсибилизированных красителем СЭ типа DSC (dye-sensitized solar cells) [3,4] и перовскитных СЭ - PSC (perovskite solar cells) [5,6].

Существенным преимуществом DSC- и PSC-фотопреобразователей является их способность сохранять достаточно высокие значения кпд при работе в условиях низкого уровня солнечной радиации и при диффузном освещении, в то время как эффективность кремниевых СЭ в аналогичных условиях значительно понижается [7-9]. Например, авторами [8] было показано, что при уменьшении интенсивности освещения с 1000 до $50 \mathrm{BT} / \mathrm{M}^{2}$ кпд DSC не понижается, а возрастает от 7-8 до 10-12\%. Эффективность СЭ вида PSC с падением уровня солнечной радиации незначительно снижается [9].

Общим в конструкции DCS- и PSC-фотопреобразователей является наличие наноструктурированного мезоскопического слоя из наночастиц диоксида титана $\left(\mathrm{TiO}_{2}\right)$, который играет роль электронпроводящего фотоэлектрода, и наноструктурная морфология которого во многом обуславливает способность СЭ к поглощению низкоинтенсивного и рассеянного светового излучения. Различия между СЭ рассматриваемого вида связаны с тем, что при конструировании PSC-фотопреобразователя на $\mathrm{TiO}_{2}$-фотоэлектрод методом спин-коутинга (spin-coating) наносится перовскитный материал, представляющий собой органо-неорганическое соединение с общей формулой $\mathrm{ABX}_{3}$, где $\mathrm{A}-\mathrm{CH}_{3} \mathrm{NH}_{3}^{+}, \mathrm{HC}\left(\mathrm{NH}_{2}\right)_{2}^{+}$, $\mathrm{B}-\mathrm{Pb}^{2+}, \mathrm{Sn}^{2+}, \mathrm{X}-\mathrm{I}^{-}, \mathrm{Br}^{-}, \mathrm{Cl}^{-}$. В отличие от DSC, где $\mathrm{TiO}_{2}$-фотоэлектрод сенсибилизируется красителем, фоточувствительный перовскитный слой способен проводить и дырки, и электроны, при этом длина диффузии заряда может достигать 1 мкм [10,11].

Следует отметить, что в целом в научной литературе слабо освещен вопрос влияния уровня солнечной радиации на работу различных типов СЭ, тогда как это имеет первостепенное значение в реальных условиях эксплуатации солнечных элементов и солнечных панелей, особенно в широтах средней и северной России [12]. Также в публикациях отсутствуют сравнительные данные по эффективностям DSC и PSC при низких интенсивностях освещения.

В нашей работе представлены результаты по конструированию и исследованию работы CЭ типа DSC и PSC на основе $\mathrm{TiO}_{2}$-фотоэлектродов в условиях изменяемой интенсивности освещения в сравнении с соответствующими параметрами для СЭ на основе кристаллического кремния (c-Si).

\section{2. Методика эксперимента}

\section{1. Солнечные элементы типа DSC}

Для конструирования DSC-фотопреобразователей в качестве подложек были использованы стекла Solaronix 
размером $2 \times 2$ см с высоким оптическим пропусканием $(T>80 \%)$, покрытые тонким проводящим слоем FTO на основе оксида олова, допированного фтором. Подложки предварительно были очищены в ультразвуковой ванне и последовательно в растворах детергента, этанола и ацетона, после чего они кипятились в $\mathrm{TiCl}_{4}$ в течение 30 мин при $70^{\circ} \mathrm{C}$ в 0.4 мМ водном растворе $\mathrm{TiCl}_{4}$ и прокаливались при $500^{\circ} \mathrm{C}$ в течение 30 мин. Фотоэлектроды в виде наноструктурированных слоев из наночастиц $\mathrm{TiO}_{2}$ наносились на подложки с последующим отжигом при $500^{\circ} \mathrm{C}$ в течение 30 мин, следуя описанной ранее методике $[13,14]$. Затем они вновь подвергались кипячению в $0.4 \mathrm{MM}$ водном растворе $\mathrm{TiCl}_{4}$ и повторному отжигу.

Процесс сенсибилизации фотоэлектродов проводился в течение 24 ч в смеси ацетонитрила и трет-бутилового спирта в соотношении $1: 1$, содержащей краситель N719 в концентрации $0.3 \mathrm{MM}$ [15]. В качестве противоэлектрода использовалась стеклянная проводящая подложка, на которую наносился раствор $\mathrm{H}_{2} \mathrm{PtCl}_{6}$ (2 мг $\mathrm{Pt}$ в 1 мл этанола) с последующим отжигом при $400^{\circ} \mathrm{C}$ в течение 15 мин [15]. При окончательной сборке CЭ типа DSC сенсибилизированный фотоэлектрод и противоэлектрод накладывались друг на друга с последующей герметизацией по периметру с помощью пленки Surylin-1702. Далее пространство между электродами через заранее просверленные в противоэлектроде отверстия заполнялось электролитом (раствор AN-50 Iodolyte, Solaronix). В результате была приготовлена серия DSC-элементов на основе мезоскопических слоев $\mathrm{TiO}_{2}$ толщиной 6.1 мкм и рабочей площадью $\sim 0.7 \times 0.7 \mathrm{cM}$.

\section{2. Солнечные элементы типа PSC}

При создании фотоэлектродов для PSC мезоскопические слои $\mathrm{TiO}_{2}$ толщиной 400 нм наносились методом спин-коутинга $[16,17]$ и подвергались отжигу при $500^{\circ} \mathrm{C}$ следующего состава: в 1 мл хлорбензола смешивалось

тыльных токосъемных контактов из золота толщиной около 50 нм, которые наносились методом термического напыления в вакууме с использованием вакуумного поста ВУП-4. Площадь рабочей области фотоэлектрода в PSC составляла $0.09 \mathrm{~cm}^{2}$.

\section{3. Методы исследования}

CЭ на основе кристаллического кремния $c$-Si размером $1.7 \times 2.1 \mathrm{~cm}$ были любезно предоставлены нам исследовательской группой Г.Г. Унтилы из НИИЯФ МГУ им. М.В. Ломоносова.

Сравнительные исследования работы СЭ вида DSC, PSC и $c$-Si проводились с использованием солнечного имитатора Abet 10500 (Abet Technologies, CША) как в условиях стандартного солнечного излучения в 1000 Вт/м² (AM1.5G), так и при изменяемой интенсивности освещения $\left(10-1000 \mathrm{BT} / \mathrm{M}^{2}\right)$. Уменьшение интенсивности освещения достигалось с помощью специальных нейтральных фильтров (Marumi, Япония), которые обеспечивали равномерное уменьшение светового потока в спектральном диапазоне от 300 до 1100 нм.

Вольт-амперные характеристики (BAX) записывались на универсальном анализаторе 4200-SCS (Keithley, США). Спектры внешней квантовой эффективности СЭ, IPCE (incident photon-to-current conversion efficiency), исследовались с использованием автоматизированной системы QEX10 (PV Measurments, CША) в диапазоне длин волн 300-900 нм.

\section{3. Экспериментальные результаты}

Структуры сконструированных нами СЭ вида DSC и PSC представлены на рис. 1. Фотоэлектроды в образцах в течение 30 мин, затем кипячению в течение 10 мин при $90^{\circ} \mathrm{C}$ в $0.2 \mathrm{MM}$ водном растворе $\mathrm{TiCl}_{4}$ и повторному отжигу при $500^{\circ} \mathrm{C}$ в течение 30 мин. Непосредственно перед нанесением фотоэлектродных слоев подложки предварительно покрывались блокирующим слоем, который предотвращал возможный электрический контакт между перовскитом и FTO-покрытием [16].

Дальнейшая сборка PSC проводилась в атмосферных условиях при высокой влажности ( 50-60\%) согласно методике, подробно описанной нами ранее [16]. Раствор перовскита $\mathrm{CH}_{3} \mathrm{NH}_{3} \mathrm{PbI}_{3}$ в диметилформамиде с последующим введением диэтилового эфира распылялся на поверхность $\mathrm{TiO}_{2}$-фотоэлектрода, который впоследствии подсушивался при $100^{\circ} \mathrm{C}$ в течение 10 мин. После остывания поверх перовскитного слоя наносился слой дырочного проводника Spiro-MeO-TAD. С этой целью использовался раствор 72.3 мг Spiro-MeO-TAD, 28.8 мкл 4-трет-бутилпиридина и 17.5 мкл раствора бис(трифторметансульфонил)имида лития Li-TSFI (520 мг Li-TSFI в 1 мл ацетонитрила). Завершающей стадией создания PSC было формирование
Dye-sensitized solar cell

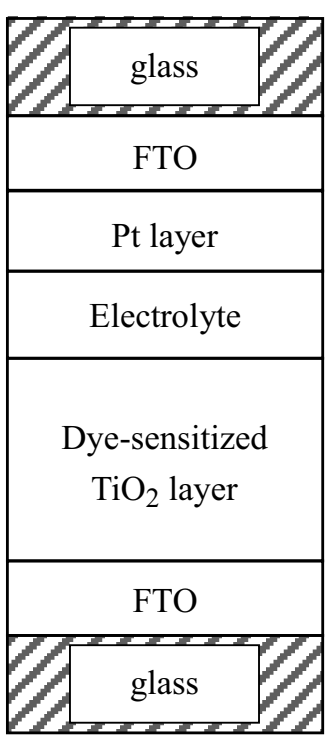

Рис. 1. Схематическое изображение конструкций СЭ типа DSC и PSC.

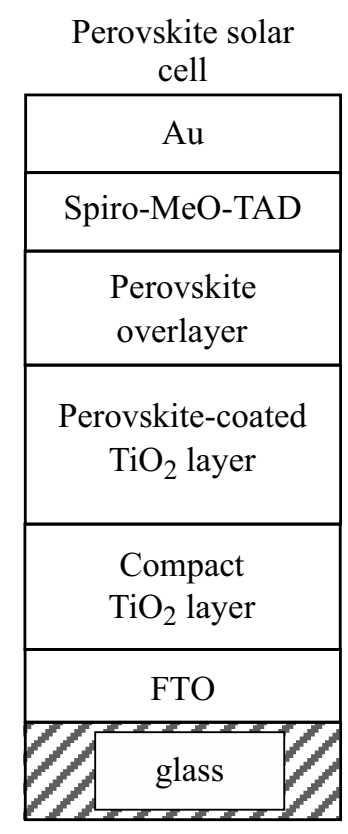

Физика и техника полупроводников, 2019, том 53, вып. 4 


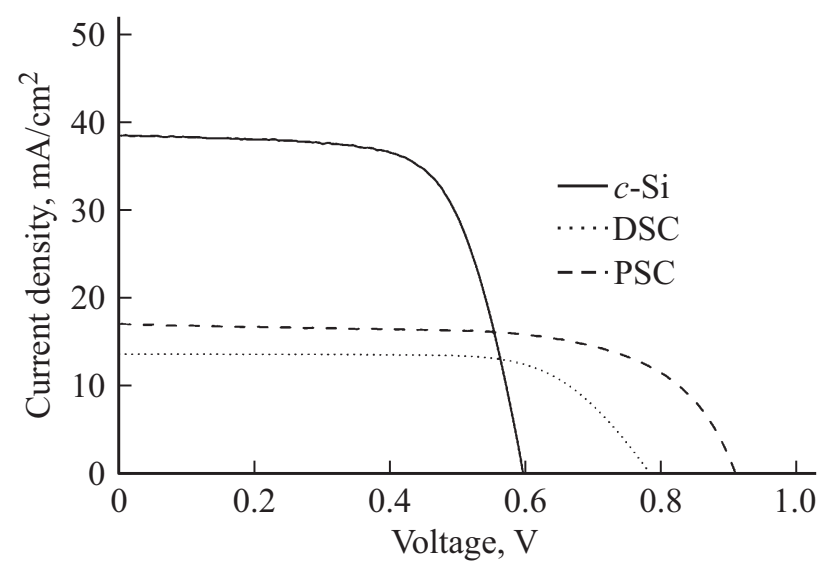

Рис. 2. ВАХ для СЭ вида $c$-Si, DSC и PSC при освещении интенсивностью $1000 \mathrm{BT} / \mathrm{M}^{2}$ (АM1.5G).

DSC и PSC представляют собой тонкие слои $\mathrm{TiO}_{2}$ толщиной 6.1 мкм и 400 нм соответственно. Для СЭ типа $c$-Si толщина фотоэлектрода составляет $\sim 200$ мкм.

BAX, полученные при интенсивности освещения $1000 \mathrm{BT} / \mathrm{M}^{2}$ (AM1.5G), для образцов разработанных нами фотопреобразователей вида DSC и PSC в сравнении с данными для СЭ типа $c$-Si представлены на рис. 2. Видно, что наибольшее значение тока короткого замыкания показывает CЭ на основе $c$-Si, в то время как максимальное значение напряжения холостого хода наблюдается для PSC-фотопреобразователя.

Значения кпд фотопреобразования $\eta(\%)$, полученные для CЭ типа DSC, PSC и $c$-Si в стандартных условиях освещения, представлены в таблице и рассчитывались по известной формуле [18]:

$$
\eta=\frac{J_{S C} V_{O C} F F}{P_{I N}} 100 \%,
$$

где $J_{S C}$ - плотность тока короткого замыкания, $V_{O C}-$ напряжение холостого хода, $F F$ - коэффициент заполнения, $P_{I N}$ - интенсивность освещения.

Как видно из таблицы, наибольшая эффективность фотопреобразования в 15.56\% наблюдается для CЭ $c$ - $\mathrm{Si}$. В данных условиях кпд образцов PSC и DSC оказывается соответственно в 1.5 и 2 раза ниже.

Важную информацию для понимания фотовольтаических свойств СЭ несут спектральные зависимости внешней квантовой эффективности, которые для всех рассматриваемых СЭ представлены на рис. 3. Видно,

Фотоэлектрические параметры для СЭ типа $c$ - $\mathrm{Si}$, DSC и PSC в стандартных условиях освещения $1000 \mathrm{BT} / \mathrm{M}^{2}$ (AM1.5G)

\begin{tabular}{c|c|c|c|r}
\hline $\begin{array}{c}\text { Тип солнечных } \\
\text { элементов }\end{array}$ & $J_{S C}, \mathrm{MA} / \mathrm{cm}^{2}$ & $V_{O C}, \mathrm{~B}$ & $F F$ & $\eta, \%$ \\
\hline$c-\mathrm{Si}$ & 38.45 & 0.60 & 0.68 & 15.56 \\
$\mathrm{DSC}$ & 13.71 & 0.78 & 0.70 & 7.45 \\
$\mathrm{PSC}$ & 17.08 & 0.91 & 0.66 & 10.20
\end{tabular}

что основной спектральный диапазон работы DSC приходится на интервал длин волн 400-600 нм, тогда как $\mathrm{C} \ni$ типа $c$-Si демонстрирует более высокие значения IPCE и более широкий оптический рабочий спектр в диапазоне 500-900нм. PSC-фотопреобразователи с рабочим интервалом длин волн от 300 до 800 нм по своим параметрам уступают кремниевым СЭ, однако превосходят DSC-элементы, что выражается в соответствующих значениях эффективности. Представленные сравнительные результаты IPCE хорошо согласуются с литературными данными и с результатами наших измерений, представленными на рис. 2 и в таблице.

Фотовольтаические характеристики для всех типов фотопреобразователей были измерены в условиях изменяемой интенсивности солнечного излучения в диапазоне $10-1000 \mathrm{~B} \mathrm{~T} / \mathrm{M}^{2}$. На рис. 4 представлены зависимости кпд СЭ типа $c$-Si, DSC и PSC от интенсивности осве-

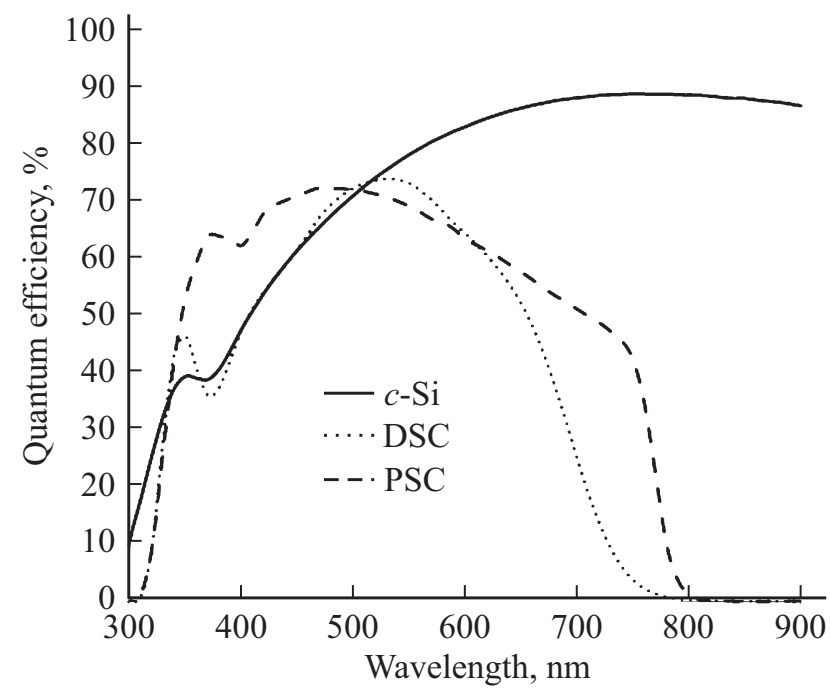

Рис. 3. Спектральные характеристики внешней квантовой эффективности (IPCE) для СЭ типа $c$-Si, DSC и PSC.

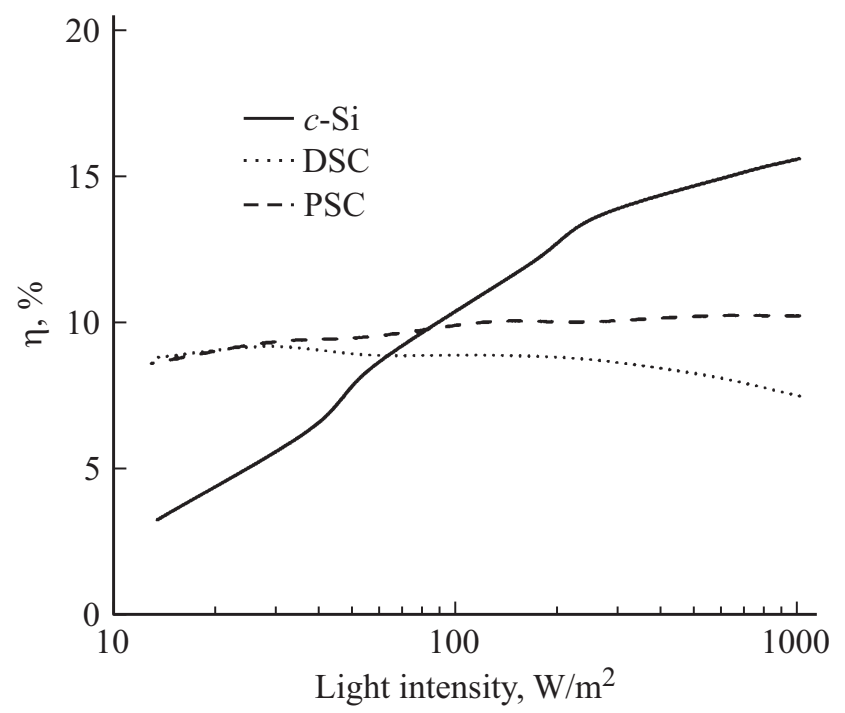

Рис. 4. Экспериментальные зависимости кпд $(\eta)$ от интенсивности освещения для СЭ типа $c-\mathrm{Si}$, DSC и PSC. 


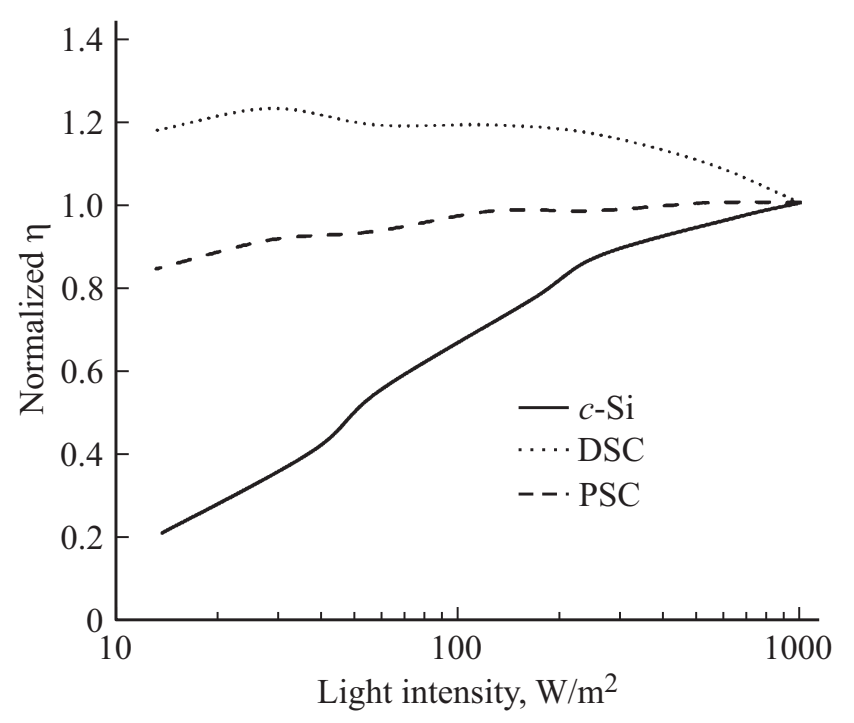

Рис. 5. Зависимость нормированных значений кпд $(\eta)$ фотопреобразования от интенсивности освещения для СЭ типа $c-\mathrm{Si}$, DSC и PSC.

щения. Видно, что эффективность кремниевого образца при уменьшении интенсивности освещения существенно падает - при освещении $10 \mathrm{BT} / \mathrm{M}^{2}$ она составляет $3.3 \%$, что в $\sim 5$ раз меньше, чем при освещении $1000 \mathrm{BT} / \mathrm{M}^{2}$ (рис. 5). В тех же условиях кпд для PSC снижается незначительно (на $\sim 20 \%$ ), в то время как кпд для DSC увеличивается в 1.2 раза (рис. 4 и 5).

Представленные на рис. 4 и 5 данные демонстрируют специфическое поведение исследуемых СЭ с наноструктурированными фотоэлектродами на основе $\mathrm{TiO}_{2}$ в условиях низкой освещенности. Анализ фотовольтаических параметров СЭ показал, что зависимость $J_{S C}$ от интенсивности освещения носит линейный характер незави- симо от типа СЭ. В то же время характер изменения значений $V_{O C}$ и $F F$ для образцов DSC и PSC значительно отличается от поведения соответствующих величин в образце $c$-Si. Как видно из рис. 6, при интенсивности освещения менее $100 \mathrm{BT} / \mathrm{M}^{2}$ наблюдается резкий спад значений $V_{O C}$ для $\mathrm{CЭ}$ типа $c$-Si, что не характерно для СЭ на основе $\mathrm{TiO}_{2}$. Принимая во внимание то, что величина $V_{O C} \sim \ln \left(J_{S C} \tau\right)$, где $\tau-$ время жизни носителей заряда, на основании полученных зависимостей значений $V_{O C}$ от интенсивности освещения можно предположить, что величина $\tau$ в DSC- и PSC-элементах слабо зависит от интенсивности освещения и количества фотогенерированных носителей заряда.

Величина $F F$ для кремниевого образца заметно ухудшается при снижении интенсивности освещения (рис. 6), тогда как в DSC- и PSC-элементах она остается практически неизменной. Последнее может говорить о том, что в условиях низкой солнечной радиации в $\mathrm{TiO}_{2}$-фотоэлектродах снижается влияние рекомбинационных процессов.

Известно, что в СЭ на основе $c$ - $\mathrm{Si}$, состоящем из слоев кристаллического кремния, фотопроцессы эффективно протекают при условии прямого (под углом 90 ) падения солнечного излучения на поверхность элемента [19]. В отличие от этого, в СЭ типа DSC и PSC (рис. 1) пористая структура мезоскопического фотоэлектрода обеспечивает эффективное поглощение и фотопреобразование как низкоинтенсивного, так и рассеянного света, падающего под различными углами к поверхности, что подтверждается представленными на рис. 4-6 результатами. Кроме того, как оказалось, толщина фотоэлектрода в $\mathrm{CЭ}$ на основе $\mathrm{TiO}_{2}$ также влияет на характер зависимости кпд от интенсивности освещения. Эффективность образца PSC, в котором толщина слоя $\mathrm{TiO}_{2}$ составляет $400 \mathrm{HM}$, хоть и незначительно, но
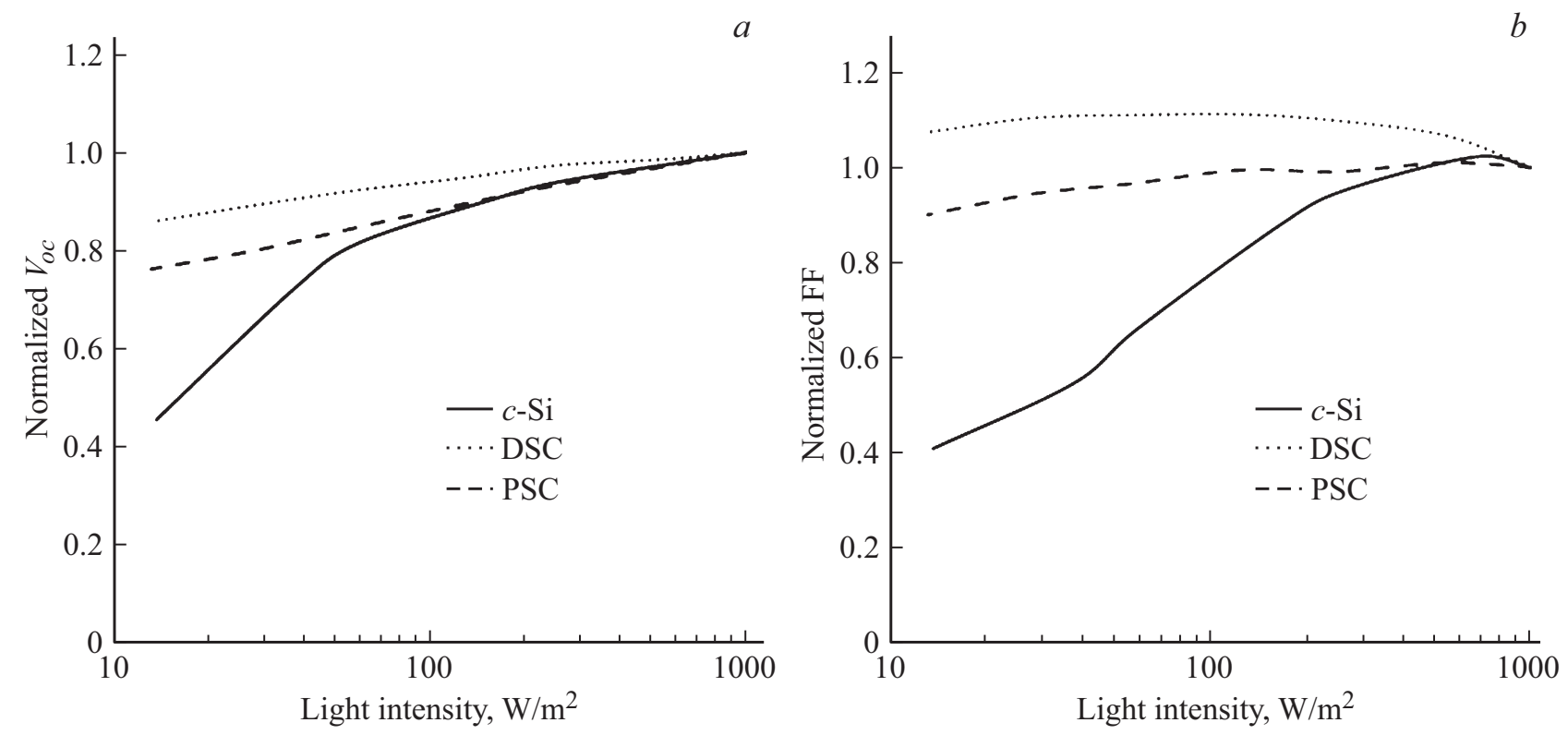

Рис. 6. Зависимость нормированных значений $V_{O C}(a)$ и $F F(b)$ от интенсивности освещения для CЭ типа $c$ - $\mathrm{Si}$, DSC и PSC. 
падает. В то же время кпд CЭ типа DSC, в структуре которого используется фотоэлектрод толщиной 6.1 мкм, улучшается с понижением интенсивности освещения.

Суммируя представленные выше результаты, можно утверждать, что эффективности фотопреобразования в CЭ типа DSC и PSC при понижении интенсивности освещения зависят от ряда факторов, включая вид используемого фоточувствительного материала, толщину электронпроводящих фотоэлектродных слоев, а также особенности морфологии и микроструктуры материала фотоэлектрода. Полученные данные свидетельствуют о том, что при низких уровнях солнечной радиации, а также в условиях рассеянного освещения наиболее эффективны СЭ с наноструктурированными фотоэлектродами на основе диоксида титана. Кроме того, значения кпд фотопреобразования и коэффициент заполнения $F F$ для образцов DSC повышаются при снижении интенсивности освещения.

\section{4. Заключение}

Сконструированы сенсибилизированные красителем и перовскитные солнечные элементы с мезоскопическими наноструктурированными фотоэлектродами на основе диоксида титана и исследованы их фотовольтаические характеристики. Сравнительные измерения эффективности элементов DSC, PSC и $c$-Si в условиях изменяемой интенсивности освещения в диапазоне $10-1000 \mathrm{BT} / \mathrm{m}^{2}$ показали преимущества DSC- и PSC-фотопреобразователей для работы в условиях низких значений солнечной радиации. Установлено, что высокие значения эффективности DSC- и PSC-фотопреобразователей в условиях низкой интенсивности освещения обусловлены наноструктурированной морфологией электронпроводящих фотоэлектродов на основе $\mathrm{TiO}_{2}$ и зависят от вида, структуры и толщины фотоэлектродного слоя. Представленные результаты демонстрируют перспективы использования перовскитных и сенсибилизированных красителем солнечных элементов для работы в реальных погодных условиях низкой и рассеянной солнечной радиации, характерных для средних и северных широт Европы и России.

Исследование выполнено при финансовой поддержке гранта Российского научного фонда (проект № 17-1901776).

\section{Список литературы}

[1] J. Jean, P.R. Brown, R.L. Jaffe, T. Buonassisi, V. Bulovic. Energy Environ. Sci., 8, 1200 (2015).

[2] K.G. Reddy, T.G. Deepak, G.S. Anjusree, S. Thomas, S. Vadukumpully, K.R.V. Subramanian, S.V. Nair, A.S. Nair. Phys. Chem. Chem. Phys., 16, 6838 (2014).

[3] B.E. Hardin, H.J. Snaith, M.D. McGehee. Nature Photonics, 6, 162 (2012).

[4] A. Nikolskaia, O. Shevaleevskiy. Handbook of Solid State Chemistry, Vol. 6 - Applications: Functional Materials (Wiley-VCH, Weinheim, 2017) p. 61.

[5] M. Gratzel. Acc. Chem. Res., 50, 487 (2017).
[6] M.A. Green, Y. Hishikawa, E.D. Dunlop, D.H. Levi, J. HohlEbinger, A.W.Y. Ho-Baillie. Progr. Photovolt.: Res. Appl., 26, 3 (2018).

[7] M. Freitag, J. Teuscher, Y. Saygili, X. Zhang, F. Giordano, P. Liska, J. Hua, S.M. Zakeeruddin, J.-E. Moser, M. Grätzel, A. Hagfeldt. Nature Photonics, 11, 372 (2017).

[8] J.-L. Lan, T.-C. Wei, S.-P. Feng, C.-C. Wan, G. Cao. J. Phys. Chem. C, 116, 25727 (2012).

[9] I. Raifuku, Y. Ishikawa, S. Ito, Y. Uraoka. J. Phys. Chem. C, 120, 18986 (2016).

[10] M.I.H. Ansari, A. Qurashi, M.K. Nazeeruddin. J. Photochem. Photobiol. C Photochem. Rev., 35, 1 (2018).

[11] H.J. Snaith. J. Phys. Chem. Lett., 4, 3623 (2013).

[12] C. Cornaro, S. Bartocci, D. Musella, C. Strati, A. Lanuti, S. Mastroianni, S. Penna, A. Guidobaldi, F. Giordano, E. Petrolati, T.M. Brown, A. Reale, A. Di Carlo. Progr. Photovolt.: Res. Appl., 23, 215 (2015).

[13] S. Kozlov, A. Nikolskaia, L. Larina, M. Vildanova, A. Vishnev, O. Shevaleevskiy. Phys. Status Solidi A, 213 (7), 1801 (2016).

[14] A.B. Nikolskaia, M.F. Vildanova, S.S. Kozlov, O.I. Shevaleevskiy. Semiconductors, 52 (1), 88 (2018).

[15] M.F. Vildanova, A.B. Nikolskaia, S.S. Kozlov, O.I. Shevaleevskiy, L.L. Larina. Techn. Phys. Lett., 44 (2), 126 (2018).

[16] O.I. Shevaleevskiy, A.B. Nikolskaia, M.F. Vildanova, S.S. Kozlov, O.V. Alexeeva, A.A. Vishnev, L.L. Larina. Russ. J. Phys. Chem., 12 (4), 663 (2018).

[17] M. Vildanova, S. Kozlov, A. Nikolskaia, O. Shevaleevskiy, N. Tsvetkov, O. Alexeeva, L. Larina. Nanosystems: Physics, Chemistry, Mathematics, 8 (4), 540 (2017).

[18] A. Luque, S. Hegedu. Handbook of Photovoltaic Science and Engineering (Chichester, John Wiley \& Sons Ltd, 2003) p. 92.

[19] R. Santbergen, R.J.C. van Zolingen. Sol. Energ. Mater. Solar Cells, 92 (4), 432 (2008).

Редактор Г.А. Оганесян

\section{Power conversion efficiencies of perovskite and dye-sensitized solar cells under various solar radiation intensities}

\section{A.B. Nikolskaia, S.S. Kozlov, M.F. Vildanova, O.I. Shevaleevskiy}

Institute of Biochemical Physics, Russian Academy of Sciences, 119334 Moscow, Russia

Abstract We present the results of a comparative study on behavior of the photovoltaic parameters in perovskite (PSC), dyesensitized (DSC) and crystalline silicon $(c-\mathrm{Si})$ solar cells under various intensities of solar radiation $\left(10-1000 \mathrm{~W} / \mathrm{m}^{2}\right)$. It was found that unlike $c$-Si, the power conversion efficiencies of PSC and DSC under low radiation intensities are comparable with the corresponding values observed under standard light intensity of $1000 \mathrm{~W} / \mathrm{m}^{2}$ (AM1.5G). We have shown that high performance of the PSC and DSC at low and diffuse lighting conditions can be explained by the properties of the nanostructured $\mathrm{TiO}_{2}$-based photoelectrodes depending on the structure, morphology and the thickness of the oxide $\mathrm{TiO}_{2}$ layers. 